\title{
AVALIAÇÃO QUÍMICA E SENSORIAL DE LINGÜIÇAS DE PESCADO TIPO FRESCAL
}

\author{
ROBERTA TARGINO PINTO CORREIA * \\ SILVANA CORREIA DE MENDONÇA ** \\ MARIA LUCILDA LIMA *** \\ PRISCILLA DINIZ DA SILVA ***
}

\begin{abstract}
A presente pesquisa teve por objetivo caracterizar quimicamente e investigar a aceitabilidade de três tipos de lingüiça preparadas a partir da associação dos seguintes ingredientes cárneos: camarão e peixe, camarão e bacon, camarão, bacon e peixe. As análises químicas incluíram determinação do teor de umidade, gordura, proteína e cinzas, enquanto a análise sensorial envolveu os testes de aceitabilidade e de preferência. A composição química mostrou-se adequada, com teores de umidade, cinzas e proteína similares a de produtos existentes no mercado e percentual lipídico reduzido, configurando produto cárneo com baixo teor de gordura. Todas as preparações analisadas tiveram boa aceitação e a formulação obtida a partir de camarão e bacon foi considerada a preferida pelo painel sensorial.
\end{abstract}

PALAVRAS-CHAVE: LINGUIÇA; PESCADO; CAMARÃO; BACON; PEIXE.

\section{INTRODUÇÃO}

O pescado contém diversos componentes com significativo valor nutricional fazendo parte da dieta alimentar de boa parte da população, sobretudo em países como o Brasil, dotado de grande extensão litorânea. Apresenta, de maneira geral, conteúdo protéico comparável à carne bovina, suína e

* Professora Assistente, Universidade Federal do Rio Grande do Norte (UFRN), Centro de Tecnologia, Departamento de Agropecuária, Campus Universitário, Lagoa Nova, Natal, RN. (e-mail: roberta@ct.ufrn.br).

** Professora, Centro Federal de Educação Tecnológica de Pernambuco, Cidade Universitária, Recife, PE. (e-mail: silvanam@novaera.com.br).

*** Alunas de Graduação, Curso de Zootecnia, UFRN, Natal, RN. 
de aves, porém com qualidade superior (SIKORSKI, KOLAKOWSKA \& PAN, 1994).

Vem crescendo no Brasil a área de carcinocultura e a Região Nordeste destaca-se pelo clima propício e área disponível, em torno de 200 mil hectares, para o cultivo. Atualmente, o Estado do Rio Grande do Norte constitui pólo produtor de grande vulto, com produção estimada de 8 mil toneladas em 2000 e área de cerca de 10 mil hectares (BALANÇO..., 2000). A espécie Penaeus vannameié cultivada quase que exclusivamente no continente americano, do sul dos Estados Unidos até o norte do Peru, além do Brasil (PAQUOTTE et al., 1998), sendo considerada a variedade que melhor se adaptou ao cativeiro em território nacional, além de apresentar vantagens como produtividade e crescimento rápido.

Lingüiça pode ser definida como produto cárneo industrializado, adicionado ou não de tecidos adiposos e ingredientes, embutido em envoltório natural ou artificial (BRASIL, 2000). Apesar de todo potencial pesqueiro brasileiro, poucos são os relatos sobre a utilização de pescado para elaboração de lingüiça frescal. O fato torna-se ainda mais relevante quando se sabe que cerca de dois terços do total do pescado mundial não é empregado para alimentação direta, e sim na elaboração de produtos derivados do pescado (ROCHA et al.,1998). Preteridos para o consumo direto, a elaboração da lingüiça frescal de camarão pode se tornar alternativa para o aproveitamento do camarão e frutos do mar de pequeno tamanho.

Formulações de lingüiça de pescado elaboradas com camarão, peixe e bacon foram avaliadas neste trabalho quanto à composição química e aceitabilidade sensorial.

\section{MATERIAL E MÉTODOS}

\subsection{MATÉRIA-PRIMA}

Foram utilizados camarões marinhos da espécie $P$. vannamei, cultivados em viveiros na Lagoa de Guaraíras, localizada a $42 \mathrm{~km}$ de Natal/RN. Adquiriu-se em estabelecimento comercial da mesma cidade, peixe da espécie Balistes carolinensis, conhecido vulgarmente como cangulo ou peixe-porco. O pescado foi mantido congelado sofrendo descongelamento prévio ao processamento. Outros ingredientes usados foram bacon, azeite de oliva e condimentos, ou seja, sal, pimenta-do-reino branca, páprica e ervas desidratadas. 


\subsection{PROCESSAMENTO}

Foram definidas três formulações variando-se a quantidade de peixe, camarão e bacon conforme Tabela 1, que constituíram três grupos experimentais: 1 - Camarão e peixe (CP); 2 - Camarão e bacon (CB); 3 Camarão, bacon e peixe (CBP).

\section{TABELA 1 - FORMULAÇÃO DAS LINGÜIÇAS DE PESCADO TIPO FRESCAL}

\begin{tabular}{lccc}
\hline Ingredientes & $\begin{array}{c}\text { Camar }{ }^{\mathrm{a}} \text { o e peixe } \\
(\mathrm{CP})\end{array}$ & $\begin{array}{c}\text { Camar }^{\mathrm{a}} \text { o e bacon } \\
(\mathrm{CB})\end{array}$ & $\begin{array}{c}\text { Camar }^{\mathrm{a}} \text { o, bacon e } \\
\text { peixe (CBP) }\end{array}$ \\
\hline Camar $^{\mathrm{a}} \mathrm{o}(\mathrm{g})$ & 500 & 500 & 500 \\
Peixe $(\mathrm{g})$ & 125 & - & 70 \\
Bacon $(\mathrm{g})$ & - & 125 & 70 \\
Azeite de oliva $(\mathrm{mL})$ & 25 & 25 & 25 \\
Sal $(\mathrm{g})$ & 20 & 20 & 20 \\
Condimentos $(\mathrm{g})$ & 10 & 10 & 10 \\
\hline
\end{tabular}

Os camarões foram descascados e limpos com água e limão, sendo então congelados. Tratamento similar foi adotado para limpeza do peixe, o qual após evisceração e retirada de escamas foi limpo com água e limão.

Após moagem em multiprocessador doméstico, o material congelado foi homogeneizado com subseqüente adição dos outros ingredientes e embutido em tripa sintética de forma artesanal. As diversas etapas do preparo destes alimentos podem ser visualizadas na Figura 1.

\subsection{METODOLOGIA ANALÍTICA}

\subsubsection{Análises Físico-químicas}

A caracterização físico-química do produto final consistiu na determinação do teor de umidade, lipídios totais, proteínas e cinzas de acordo com os métodos analíticos do INSTITUTO ADOLFO LUTZ (1985). 


\subsubsection{Análises Sensoriais}

Participaram dos testes de aceitação e preferência, realizados segundo CHAVES \& SPROESSER (1993), trinta provadores não-treinados de ambos os sexos, escolhidos aleatoriamente entre diferentes faixas etárias e classes sociais. Para o teste de aceitabilidade foi empregada a escala de atitudes com nove categorias $(9=$ comeria sempre; $5=$ comeria, mas não compraria; 1 = não comeria de jeito nenhum). A preferência foi avaliada mediante teste de ordenação, no qual cada provador enumerou as amostras (1 a 3) de acordo com a ordem de sua preferência.

\section{FIGURA 1 - FLUXOGRAMA DO PROCESSAMENTO DAS LINGÜIÇAS DE PESCADO}

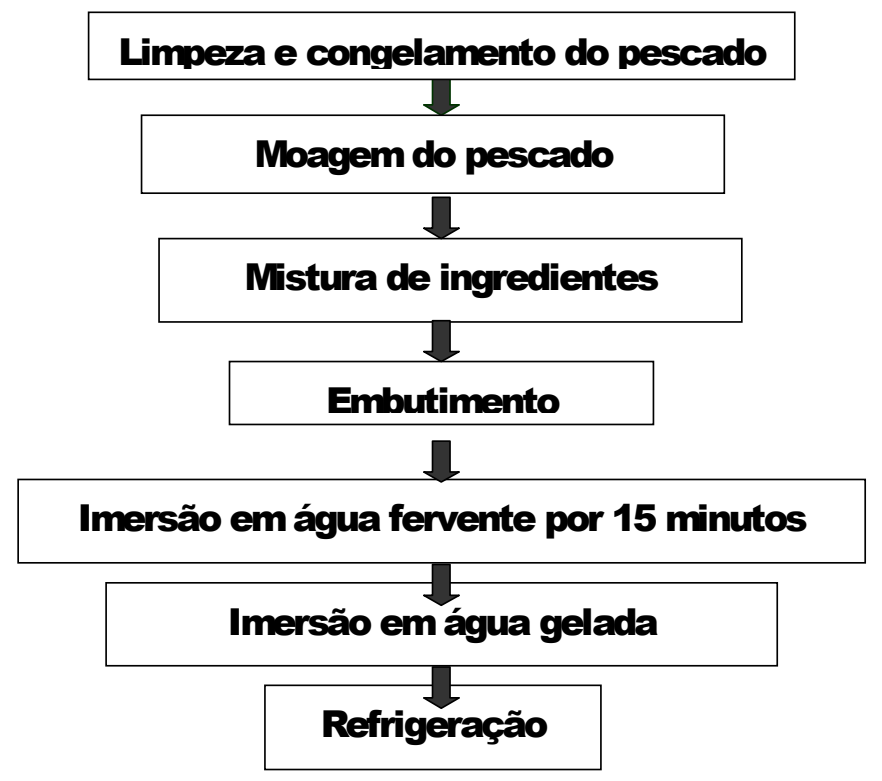

\subsubsection{Tratamento Estatístico}

As análises físico-químicas foram realizadas em triplicata, com resultados expressos como média \pm desvio padrão. A análise de variância (ANOVA) e o teste de Tukey, aos níveis de significância de 1 e $5 \%$, foram aplicados na investigação das diferenças entre os grupos nas análises físico-químicas 
e no teste de aceitabilidade, respectivamente. Foram construídos histogramas de freqüência a partir dos resultados da aceitabilidade e o teste de Friedman foi utilizado no tratamento dos dados do teste de preferência. As análises estatísticas foram realizadas utilizando-se 0 software Statistica 5.0 (STATSOFT, USA, 1995).

\section{RESULTADOS E DISCUSSÃO}

\subsection{COMPOSIÇÃO QUÍMICA}

Os resultados da composição química dos grupos experimentais camarão e bacon (CB), camarão e peixe (CP) e camarão, bacon e peixe (CBP) estão apresentados na Tabela 2. Considerando o que o Regulamento Técnico de Identidade e Qualidade de Lingüiça (BRASIL, 2000) preconiza em relação à lingüiça frescal, as formulações $C B$ e CBP atenderam aos requisitos de umidade, proteínas e gorduras, enquanto que o produto $\mathrm{CP}$ apresentou umidade acima do limite máximo permitido. Tal fato pode ser explicado pelo teor de gordura da formulação, associado ao alto nível de umidade da matéria-prima utilizada: camarão $74,2 \%$ (ROCHA et al., 1998) e peixe cangulo 77,0\% em média (BADOLATO et al., 1994).

\section{TABELA 2 - COMPOSIÇÃO QUÍMICA DAS TRÊS FORMULAÇÕES DE LINGÜIÇA DE PESCADO TIPO FRESCAL}

\begin{tabular}{lllll}
\hline Formula ${ }^{\mathrm{a}} \mathrm{o}$ & Umidade (\%) & Prote na (\%) & Lip dios (\%) & Cinzas (\%) \\
\hline $\mathrm{CB}$ & $68,50 \pm 0,14^{\mathrm{a}}$ & $12,66 \pm 0,18^{\mathrm{a}}$ & $7,54 \pm 0,99^{\mathrm{a}}$ & $4,15 \pm 0,00^{\mathrm{a}}$ \\
$\mathrm{CP}$ & $75,30 \pm 0,00^{\mathrm{b}}$ & $15,23 \pm 0,13^{\mathrm{a}}$ & $0,90 \pm 0,10^{\mathrm{b}}$ & $3,74 \pm 0,07^{\mathrm{a}}$ \\
$\mathrm{CBP}$ & $67,45 \pm 1,06^{\mathrm{a}}$ & $14,30 \pm 1,05^{\mathrm{a}}$ & $6,70 \pm 0,81^{\mathrm{a}}$ & $3,17 \pm 0,08^{\mathrm{b}}$ \\
\hline
\end{tabular}

Valores seguidos por letras diferentes na mesma coluna apresentam diferença significativa $(p<0,01)$.

Os níveis de proteína e cinzas mostraram-se praticamente idênticos, com significativa redução no teor de cinzas da formulação CBP.

As três formulações, sobretudo o grupo experimental CP, apresentaram níveis de gordura abaixo dos $30 \%$ estabelecidos no referido Regulamento, o que valoriza o produto, face às restrições relativas ao consumo de gorduras por grande parte da população. Neste sentido, FISHER et al. (2000) afirmaram que elevada proporção de carne magra associada à baixa incorporação de gordura são, muitas vezes, requisitos decisivos 
para o estabelecimento da qualidade de lingüiças e produtos similares.

As formulações CB e CBP, nas quais foram empregadas bacon (produto rico em lipídios), mostraram teores de gordura superiores à terceira formulação (CP), cujos níveis de gordura podem ser justificados pelo baixo conteúdo de lipídios do peixe cangulo que, varia entre $0,9 \%$ e 1,3\%, segundo BADOLATO et al. (1994). Além disso, a composição lipídica da porção muscular do camarão $P$. vannamei, de acordo com ROCHA et al. (1998), apresenta valores próximos a 1\%. A formulação CP parece satisfatória, não só em termos de redução dos níveis de gordura do produto final, mas também em relação à qualidade deste constituinte. As gorduras existentes no pescado são reconhecidamente ricas em ácidos graxos insaturados, quando comparadas às gorduras vegetais e de animais terrestres, conforme explica SILVA (1993). Fato também verificado por KARAKOLTSIDIS et al. (1995) que constataram elevado teor de ácidos graxos insaturados em crustáceos, peixes e moluscos capturados no Mediterrâneo. Além disso, as gorduras do pescado são digeridas facilmente e assimiladas rapidamente pelos tecidos do organismo.

Em trabalho recente, PEREIRA et al. (2000) analisaram diferentes marcas comerciais de salsichas formuladas com frango, Chester ${ }^{\circledR}$ e peru, comparando-as com produtos formulados com carne bovina. A composição das amostras mostrou-se comparável aos resultados aqui encontrados, à exceção dos teores de gordura notadamente superiores para as salsichas de carne bovina, frango e Chester ${ }^{\circledR}$. A salsicha de peru foi a que mais se assemelhou às lingüiças de pescado avaliadas no presente trabalho, com valores médios de umidade, proteína, cinzas e gordura de $70,9 \%, 15,1 \%, 3,37 \%$ e $4,06 \%$, respectivamente.

Tendo em vista a maneira decisiva com que influencia a capacidade de retenção de umidade e, conseqüentemente, a textura e a estabilidade do produto final é importante conhecer a relação umidade/proteína (U/P) de embutidos cárneos (ALENCAR, 1994). Os produtos formulados apresentaram relação U/P de 5,41, 4,94 e 4,71, respectivamente para os grupos CB, CP e CBP. De acordo com o Regulamento de Inspeção Industrial e Sanitária de Produtos de Origem Animal - RIISPOA (BRASIL, 2001), a máxima relação permitida para produtos cárneos emulsionados é de 3,5. Observa-se que os valores aqui encontrados situaram-se acima do permitido. Da mesma maneira, MELO FILHO \& GUERRA (1998) detectaram relações umidade/proteína superiores a 3,5 para a totalidade de amostras de mortadela e salsichas de diferentes marcas comerciais consumidas em Recife-PE. Este fato, segundo GOMIDE et al. (1987), pode ser 
considerado benéfico à estabilidade da emulsão em salsichas. Tais autores afirmaram que dentro de certos limites, quanto maior a relação U/P na formulação, maior a extração protéica e, conseqüentemente, mais estável será a emulsão.

\subsection{ANÁLISE SENSORIAL}

Um dos fatores críticos para o desenvolvimento de novos produtos alimentícios é a aceitabilidade por parte dos consumidores. Como a maioria das respostas do teste empregado situou-se entre as quatro últimas categorias da escala de atitudes, correspondendo a "Comeria sempre" até "Comeria agora", pode-se considerar que o produto obteve boa aceitação. A avaliação positiva foi sentida sobretudo para a formulação CB, que alcançou $76,7 \%$ das respostas neste patamar, seguido de $70 \%$ e $60 \%$, respectivamente, para as formulações CBP e CP (Figura 2).

\section{FIGURA 2 - HISTOGRAMA DE FREQÜÊNCIA DOS ESCORES DE ACEITABILIDADE DE LINGÜIÇAS DE PESCADO}

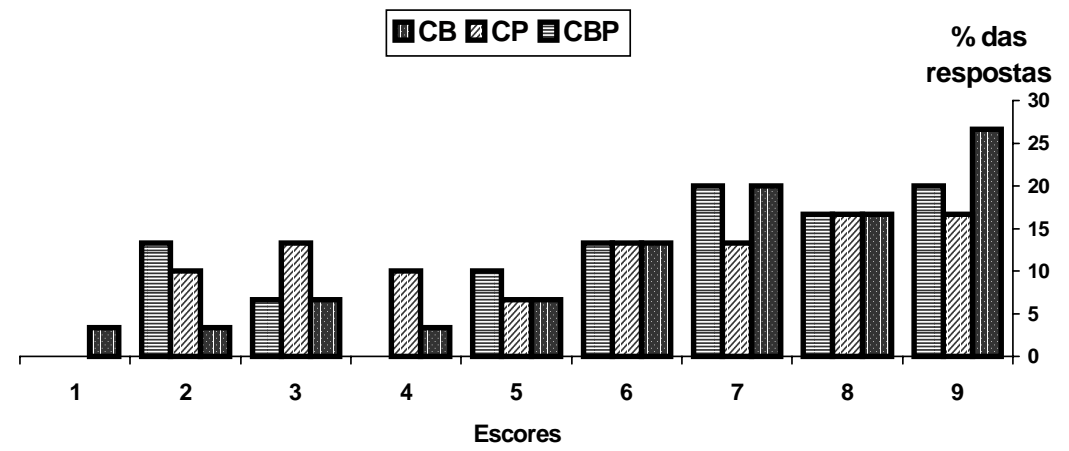

1 = não comeria de jeito nenhum; 2 = sem opções, comeria; 3 = comeria, se disponível; 4 = não gosto, mas comeria; 5 = comeria, mas não compraria; 6 = comeria agora; 7 = comeria freqüentemente; 8 = comeria muito freqüentemente; $9=$ comeria sempre.

Não foi detectada diferença significativa $(p<0,05)$ quanto à aceitabilidade das três formulações cujas médias 6,7 e 6 , respectivamente, para os produtos $\mathrm{CP}, \mathrm{CB}$ e CBP evidenciaram boa aceitação dos mesmos, com possibilidade de consumo freqüente. 
Os resultados do teste de preferência revelam tendência dos provadores a preferirem formulações contendo bacon, o qual apresenta sabor forte e característico dos embutidos tradicionais. A formulação de camarão e bacon revelou-se a preferida, enquanto que a com camarão e peixe apresentou baixo índice de predileção (Figura 3).

\section{FIGURA 3 - RESULTADOS DO TESTE DE PREFERÊNCIA PARA LINGÜIÇAS DE CAMARÃO E PEIXE (CP), CAMARÃO E BACON (CB) E CAMARÃO, BACON E PEIXE (CBP)}

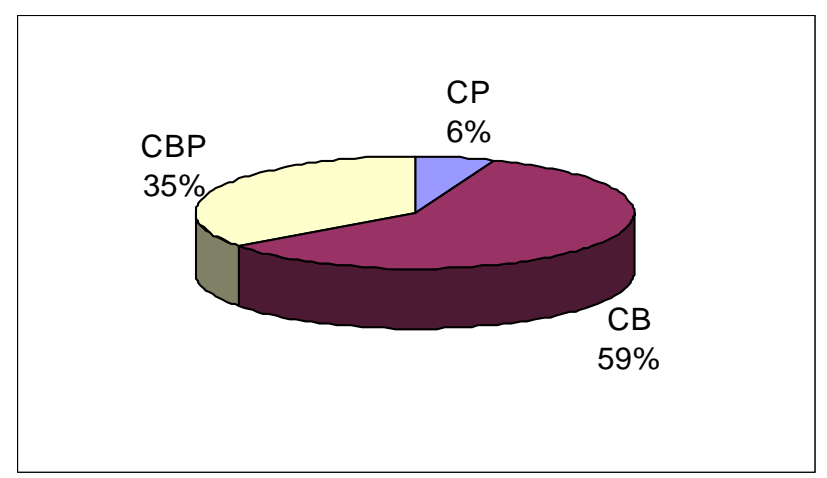

\section{CONCLUSÃO}

A composição química dos produtos avaliados mostrou-se adequada e em consonância com o estabelecido pela Legislação para lingüiças frescais produzidas com matérias-primas convencionais. Vale ressaltar o baixo teor lipídico encontrado, configurando alimento com baixo teor de gordura, sobretudo a formulação contendo camarão e peixe (CP). Todas as formulações apresentaram aceitabilidade satisfatória, sendo a formulação obtida a partir de camarão e bacon (CB) a preferida pelos participantes do painel sensorial.

\section{Abstract}

\section{CHEMICAL AND SENSORIAL EVALUATION OF FRESH FISH SAUSAGES}

The aim of the present research was to evaluate the chemical composition and the sensorial acceptability of three types of sausages prepared by the association of the following meat ingredients: fish and shrimp, shrimp and bacon, shrimp, bacon and fish. 
The chemical analysis included moisture, fat, protein and ashes determination however the sensorial analysis involved acceptability and preference tests. The chemical composition was adequate with moisture, ashes and protein contents similar to the products already existent in the market and reduced lipid percentage, configuring a meat product with low fat index. All the preparations assayed had good acceptability and the formulation prepared with shrimp and bacon was preferred by the sensorial panel.

KEY-WORDS: SAUSAGE; FISH; SHRIMP; BACON; FISH MEAT.

\section{REFERÊNCIAS}

1 ALENCAR, N. Importância da matéria-prima na elaboração de produtos cárneos. In: CURSOS rápidos na tecnologia de produtos cárneos. Belo Horizonte: CETEC, 1994. p. 7-12.

2 BADOLATO, E.S.G.; CARVALHO, J.B.; MELLO, M.R.P.A.; TAVARES, M.; CAMPOS, N.C.; AUED-PIMENTEL, S.; MORAIS, C. Composição centesimal, de ácidos graxos e valor calórico de cinco espécies de peixes marinhos nas diferentes estações do ano. Revista do Instituto Adolfo Lutz, v. 54, n.1, p. 27-35, 1994.

3 BRASIL. Ministério da Agricultura. Instrução Normativa n. 4, de 31 de março de 2000. Aprova os regulamentos técnicos de identidade e qualidade de carne mecanicamente separada, de mortadela, de lingüiça e de salsicha. Diário Oficial [da] República Federativa do Brasil, Brasília, 5 de abril de 2000. Seção 1, p. 6-10.

4 BRASIL. Ministério da Agricultura. Departamento Nacional de Inspeção de Produtos de Origem Animal. Regulamento de inspeção industrial e sanitária de produtos de origem animal. Disponível em <http://www.agricultura.gov.br/sda/dipoa>. Acesso em: 6 fev. 2001.

5 CHAVES, J.B.P.; SPROESSER, R.L. Práticas de laboratório de análise sensorial de alimentos e bebidas. Viçosa: UFV, 1993. $81 \mathrm{p}$.

6 FISHER, P.; MELLETT, F.D.; HOFFMAN, L.C. Halothane genotype and pork quality. 3. Comminuted meat products derived from the three halothane genotypes. Meat Science, v. 54, n. 1, p. 113-117, 2000.

7 GOMIDE, L.A.M.; PEREIRA, A.S.; GOMES, J.C. Efeito da relação umidade:proteína sobre a estabilidade da emulsão de salsichas enlatadas. Boletim SBCTA, v. 21, n. 3/4, p. 170-178, 1987. 
8 BALANÇO anual: Rio Grande do Norte. Gazeta Mercantil, São Paulo, ano 3, n. 3, p. 38-39, 2000.

9 INSTITUTO ADOLFO LUTZ. Normas Analíticas do Instituto Adolfo Lutz: métodos físicos e químicos para análise de alimentos. 3.ed. São Paulo, 1985.

10 KARAKOLTSIDIS, P.A.; ZOTOS, A.; CONSTANTINIDES, S.M. Composition of the commercially important mediterranean finfish, crustacean and molluscs. Journal of Food Composition and Analysis, v. 8, n.3, p. 258-273, 1995.

11 MELO FILHO, A.B.; GUERRA, N.B. Avaliação da qualidade de produtos cárneos: salsichas e mortadelas comercializadas na Região Metropolitana do Recife. In: CONGRESSO BRASILEIRO DE CIÊNCIA E TECNOLOGIA DE ALIMENTOS, 1998, Rio de Janeiro. Anais... Rio de Janeiro: SonoPress, 1998. 1 CD.

12 PAQUOTTE, P.; CHIN, L.; MARTIN, L.M.; LEMOS, E.; STERN, M.; TOSTA, G. Intensive culture of shrimp Penaeus vannamei in floating cages: zootechnical, economic and environmental aspects. Aquaculture, v. 164, n.1-4, p. 151-164, 1998.

13 PEREIRA, N.R.; TARLEY, C.R.T.; MATSUSHITA, M.; SOUZA, N.E. Proximate composition and fatty acid profile in Brazilian poultry sausages. Journal of Food Composition and Analysis, v. 13, n.6, p. 915-920, 2000.

14 ROCHA, M.M.R.M.; NUNES, M.L.; FIOREZE, R. Composição química da porção muscular e da farinha de resíduos do camarão marinho Penaeus vannamei. In: CONGRESSO BRASILEIRO DE CIÊNCIA E TECNOLOGIA DE ALIMENTOS, 1998, Rio de Janeiro. Anais... Rio de Janeiro: SonoPress, 1998. (CD).

15 SIKORSKI, Z.E.; KOLAKOWSKA, A.; PAN, B.S. Composición nutritiva de los principales grupos de organismos alimenticios marinos. In: SIKORSKI, Z.E. (Ed.). Tecnologia de los productos del mar: recursos, composicion nutritiva y conservacion. Zaragoza: Acribia, 1994. Cap 3, p. 41-72.

16 SILVA, C.R. O pescado como alimento. Minas Gerais: UFV, 1993. $15 \mathrm{p}$.

17 STATSOFT. Statistica for Windows 5.0. Oklahoma, 1995. 